\title{
A Logística Hospitalar como diferencial competitivo: Um estudo de caso em um hospital privado de baixa e média complexidade na cidade deImperatriz-MA
}

\author{
Márcia Lima dos Santos Cruz "i, Josiano César de Sousa ${ }^{2}$
}

\begin{abstract}
Resumo: A logística é um dos fatores principais para a prestação de serviços em hospitais, através de um breve estudo é possível observar que uma má gestão hospitalar faz com que um pequeno erro gere um grande problema na unidade de saúde. Diantedas dificuldades enfrentadas com o grande excesso de quantitativo de materiais e medicamentos, com influencia principalmente no quantitativo financeiro do estoque, torna-se importante melhorar os processos nessa área do hospital. A questão problema envolve buscar resposta para o seguinte questionamento: em que medida falhas na logística hospitalar podem afetar a competitividade mercadológica de um hospital de baixa e média complexidade? O objetivo deste estudo é destacar a importância da logística hospitalar para a melhoria da competitividade de um hospital privado de baixa e média complexidade. A metodologia adotada foi o estudo de caso, realizado em um hospital privado de baixa e média complexidade na cidade de Imperatriz através de estudos exploratórios descritivos. Os resultados revelam a sistemática da logística hospitalar como diferencial competitivo, bem como suas respectivas atividades descritas no mapeamento de processos como: aquisição, estocagem e distribuição interna.
\end{abstract}

Palavras-Chave: Logística. Atividades logísticas. Logística hospitalar. Hospital. Gestão de compras. Competitividade.

\section{Hospital Logistics as a competitive differential: A case study in a private hospital of low and medium complexity in the city of Imperatriz-MA}

\begin{abstract}
Logistics is one of the main factors for the provision of services in hospitals. Through a brief study, it is possible to observe that hospital mismanagement causes a small error to generate a bigger problem in the health unit. Given the challenges faced with the large excess of materials and medicines, with the maininfluence on the financial quantity of the stock, it is important to improve the processes in this area of the hospital. The problem question involves seeking an answer to the following question: to what extent can failures in hospital logistics affect the market competitiveness of a low and medium complexity hospital? This study aims to highlight the importance of hospital logistics to improve the competitiveness of a private hospital of low and medium complexity. The methodology adopted was the case study, carried out in a private hospital of low and medium complexity in the city of Imperatriz throughdescriptive exploratory studies. The results reveal the systematics of hospital logisticsas a competitive differential as well as their respective activities described in themapping of processes such as acquisition, storage, and internal distribution.
\end{abstract}

Keywords: Logistics. Logistical activities. Hospital logistics. Hospital. Purchasing management. Competitiveness.

\footnotetext{
${ }^{1}$ Acadêmica do curso de Bacharelado em Administração da Unidade de Ensino Superior do Sul doMaranhão (UNISULMA). E-mail: marcyalima19@gmail.com

${ }^{2}$ Orientador. Dr. em Engenharia de Produção e Sistemas
} 


\section{Introdução}

Desde o fim da Segunda guerra mundial, com o sucesso que os soldados obtiveram na tentativa de gerir os seus suprimentos, as empresas perceberam a importância de ter um departamento para gerenciar a logística. A partir das décadas de 1950 e 1960, as empresas começam a se preocupar com a satisfação do cliente. Foi a partir daí, devido às novas atitudes dos consumidores, que surgiu o conceito de logísticacomercial. Na década de 1970, conceitos como MRP (Material Requeriments Planning) foram consolidados (NOBREGA, 2010).

A logística é o elo que liga o planejamento das atividades desde o início do processo até seu destino final visando um mesmo objetivo, dessa forma a realização das etapas do processo devem acontecer de forma sincronizada, visto que a falha ou divergência de informações entre elas provoca problemas em toda a ação (CALIXTO et al., 2019).

No setor hospitalar a logística tem papel importante na administração de materiais onde o trabalho é feito por meio de pessoas para entregar o material certo ao cliente certo, na hora e nas quantidades certas sempre identificando as melhores condições para a unidade hospitalar, e para que isso ocorra de forma eficiente é importante estabelecer ações como planejamento, controle e outras informações relacionadas ao fluxo de materiais tanto dentro quanto fora da unidade, esse processo degerir todas as etapas necessárias para o funcionamento efetivo da unidade hospitalar se projeta a resguardar e reestabelecer a saúde dos pacientes. A logística hospitalar tem também a finalidade de suprir e atender as demandas por atribuições com todos os tipos de materiais necessários ao melhor funcionamento das atividades em uma organização hospitalar, onde o volume do lote comprado provoca consequências que podem prejudicar a eficiência operacional organizacional (BARBIERI et al., 2013).

Um dos problemas mais comuns é a falta de material e medicamento provindade uma má logística hospitalar em gestão de estoque. Problemas como este afetam em toda a estrutura hospitalar e consequentemente na qualidade dos serviços oferecidos na organização hospitalar. Diante do exposto, o seguinte problema de pesquisa pode ser levantado: em que medida falhas na logística hospitalar podem afetar a competitividade mercadológica de um hospital de baixa e média complexidade? Para buscar resposta a este questionamento, o presente artigo foi elaborado com o objetivo de destacar a importância da logística hospitalar para a melhoria da competitividade de um hospital privado de baixa e media complexidade. Para cumprir com este objetivo, o artigo foi elaborado através de um estudo de caso realizado em um hospital de baixa e média complexidade localizado em Imperatriz-MA e apresenta a seguinte estrutura: a seção 2 apresenta o referencial teórico, a seção 3 é apresentada os 
procedimentos metodológicos, a seção 4 discutidos os resultados e análise da pesquisa e por fim a 5 seção com as considerações finais.

Como principais resultados, o artigo permitiu constatar que a logística hospitalar é um diferencial competitivo, assegurando diferenciais estratégicos com vantagens oferecidas por um sistema de logística hospitalar, visando principalmente a redução de custos, além de promover a facilitação dos processos burocráticos, organização de seu espaço físico, promover a melhoria da comunicação e relacionamento com fornecedores, colaboradores e principalmente com pacientes. Ao final, o artigo apresenta suas limitações e recomendações para a realização de futuras pesquisas.

\section{Referencial Teórico}

\section{Logística empresarial}

A evolução dos estudos sobre logística cresceu exorbitantemente a partir do ano de 1917, quando o tenente coronel Thorpe elaborou teorias no livro de sua autoria "Logística Pura: a ciência da preparação para a guerra", desde então a logísticas e conceitos evoluíram. A logística é tratada como um diferencial competitivo que busca melhorar seus processos e assim conseguir vantagens sobre seu concorrente, no entanto ao longo do tempo ela tem evoluído e passado de ações isoladas para ações sinérgicas (PORTOGENTE, 2018).

De acordo com Netto (2003), dentre os seus vários conceitos, logística é a parte da arte da guerra que trata do planejamento e realização de projetos, desenvolvendo atividades afim de melhorar sistemas operacionais e administrativos. A maior contribuição da logística para o dia a dia da empresa é o valor agregado aos produtos através dos serviços prestados ao cliente.

A logística empresarial é responsável pela aquisição, movimentação, armazenagem e entrega dos produtos, ela se dá da necessidade corporativa de reduzir e até eliminar falhas no fornecimento de produtos para aprimorarem a operação logística até seu destino final, ou seja, ao consumidor. Na logística empresarial é utilizadoferramentas de gestão que aumentam a qualidade das entregas e melhoram seu profissionalismo (SENIOR, 2019).

O objetivo da logística empresarial é alcançar e disponibilizar os bens ou serviços no lugar adequado, na hora certa e nas condições desejadas, na medida em que beneficia também os resultados da empresa, especialmente do ponto de vista dos custos (OLIVEIRA, 2011). 


\section{Principais Atividades Logísticas}

Há muito tempo as empresas buscam agilidade em seus processos. A empresa deve atender as expectativas de seus clientes, por isso é de extrema importância conquistar espaço no mercado por meio de produtos e serviços de alta qualidade, além da importância de entregas dentro do prazo. Uma logística eficaz só trará resultados positivos para a organização (CHASTAGNIER, 2013).

A logística planejada envolve todos os departamentos da empresa, desde a aquisição de matéria prima até os produtos acabados, portanto, a importância da logística está na base do planejamento estratégico da empresa, fato este que representa um grande diferencial para a manutenção da competitividade no mercado se destacando da concorrência (CHASTAGNIER, 2013).

Existem várias atividades logísticas que são importantes para o alcance do maiornível de serviço com o menor custo. As atividades logísticas se dividem basicamenteem dois tipos, atividades primarias e de apoio.

\section{Atividades Primarias}

Atividades primarias são aquelas que respondem pela maior parte do custo totale é a base para o acionamento de outras atividades. São elas o transporte, manutençãode estoque e processamento de pedidos (COSTA, 2018).

\section{- Transporte}

As atividades de transporte estão relacionadas a diversos meios de transporte de produtos e insumos, portanto, as atividades de transporte são muito importantes para o processo logístico e ainda arcam com a maior parte dos custos logísticos da empresa. É importante ressaltar que o transporte agrega valor ao produto, pois é outro aspecto importante que está devidamente posicionado para atender a demanda, e quanto a outro aspecto importante são os modais disponíveis que temos em escala global que seguindo pesquisa da Confederação Nacional de Transportes (CNT), ainda temos uma grande predominância pelo modal rodoviário (61\%), seguido do ferroviário (21\%), aquaviário (14\%), dutoviário (14\%) e aeroviário (1\%), ou seja, uma tendência de multimodalidade (MEIRIM, 2017). 


\section{- Manutenção de Estoque}

Para Fonseca (2018), essa atividade permite que os produtos sejam fornecidos aos clientes de acordo com suas necessidades para entrega imediata, o que normalmentesó é possível se um nível mínimo de estoque de produtos for mantido, pode-se dizer queesses estoques funcionam como um amortecedor entre a oferta e a demanda, poisimpedem que pedidos feitos pelos clientes deixem de ser atendidos.

\section{- Processamento de Pedidos}

Essa atividade é uma ação que inicia a movimentação do produto a pedido do cliente, mesmo que não seja uma atividade que represente um custo elevado, ainda assim está diretamente relacionada com o nível de serviço prestado aos clientes, sendo, portanto, o maior desafio enfrentado pelos profissionais de logística está em reduzir o ciclo de pedidos que é o tempo entre o pedido feito pelo cliente e o mesmo ser entregue.É muito importante ter um sistema eficiente de recebimento de pedidos e entrega dos produtos ao consumidor (MEIRIM, 2017).

\section{Atividades De Apoio}

Atividades de apoio são atividades essenciais para a continuidade das atividades primarias, são elas armazenagem, manuseio de materiais, embalagens, suprimentos, planejamento e sistema de informação, atividades ligadas a devoluções e vendas de resíduos da produção (COSTA, 2018).

\section{- Armazenagem}

No processo de armazenagem todos os itens de almoxarifado são considerados necessários para exigir maior racionalidade para manter o estoque dos itens, e todos os itens em armazenagem representam recurso financeiro, capital. E se esta atividade não for realizada de forma correta ela pode se tornar uma grande fonte de prejuízos (NASCIMENTO, 2019). 


\section{- Manuseio de Materiais}

O manuseio de materiais, em seu conceito amplo, abrange o movimento dos materiais no local de armazenamento, desde a fase receptora do artigo (incluindo o movimento interno dentro do armazém) até o momento de saída. Desta forma, ele está associado ao armazenamento e também manter estoques, além de produtos acabados e pode ser relacionado à transferência de um depósito para outro (PORTOGENTE, 2016).

\section{- Embalagem}

A embalagem é um recipiente ou um tipo de proteção temporária para um produto, sua utilização decorre em proteger para não causar mau funcionamento e perdas, facilitar o manuseio, o uso, o armazenamento e podem ser reutilizados oureciclados. Para a logística a embalagem traz informações importantes sobre treinamento, transporte, peso, posição, perigo e empilhamento, além de outro cuidado para se observar: espaço ocupado, cubagem e ergonomia (NASCIMENTO, 2019).

\section{- Suprimentos}

Seu desempenho é amplo com a abordagem na aquisição, matérias-primas ebens e serviços da empresa para operação, a logística de suprimentos é uma administração e planejamento de elementos que serão precisos em todo o processo para o cliente final. Sendo assim, coordena a aquisição de objetos de acordo com as necessidades da empresa, além de analisar a disponibilidade de materiais para planejamento, análise de ações disponíveis, seleciona entrega, elabora pré-pedidos, negocia condições de pagamento e condições contratuais, plano de entrega, frequências, processos e questões de controle, trabalha a relação entre diferentes setores e controla recebimentos (NASCIMENTO, 2019).

\section{- Planejamento}

Para ativar atividades de produção/aquisição, um planejamento prévio dos montantes a serem comprados é necessário, na indústria o PCP: análise de planejamentoe controle de produção para cada produto, prognóstico de demanda de mercado, montantes disponíveis em estoque, capacidade de produção instalada e disponível, e lotemínimo de produção/compra. Com base na análise dessas variáveis, se define o valor para produzir/compra, se for produzido internamente, ainda é necessário identificar a quantidade de matéria-prima necessária para a 
produção, e, nesse sentido, os montantes disponíveis em estoque e se necessário gerado uma ordem de compra (MEIRIM, 2012).

\section{Sistema de Informação}

Ter informações sobre o auxílio de tomada de decisão é essencial para o profissional de Logística, nesse sentido, é importante fornecer informações de preferência no banco de dados integrado para clientes, concorrentes, volumes de vendas,inventários, custos associados a cada atividade armazenamento, transporte,processamento de pedidos e o uso de tecnologia de informação esta cada vez mais ligada à logística, por isso os profissionais que atuam nesta área precisam conhecer as ferramentas que os auxiliam no processo de análise e tomada de decisão (MEIRIM, 2012).

\section{Hospital e sua Classificação}

Segundo a definição do Ministério da Saúde do Brasil:

O termo hospital se refere a um conjunto muito heterogêneo de estabelecimentos de saúde, unidades de diferentes portes, que podem oferecer uma variada gama de serviços e atividades e desempenhar funções muito distintas no âmbito da rede de atendimento à saúde. Entretanto, os estabelecimentos possuem uma característica em comum: a prestação de cuidados de saúde a pacientes internados em leitos hospitalares durante as 24 horas do dia. (MINISTÉRIO DA SAÚDE, 2020).

Outra definição que encontramos é no manual de orientações para o cadastramento de hospitais no CNES:

Estabelecimento de saúde dotado de internação, meios diagnósticos e terapêuticos, com o objetivo de prestar assistência médica curativa e de reabilitação, podendo dispor de atividades de prevenção, assistência ambulatorial, atendimento de urgência/emergência e de ensino/pesquisa. (GOMES Et al, 2007).

O hospital é classificado em pequeno (até 50 leitos), médio (de 50 a 150), grande(de 150 a 400) e especial (até 400). O nível de complexidade do programa é diretamente proporcional ao tamanho e grau de sofisticação tecnológica da empresa (PORTAL EDUCAÇÃO, 2020). 
Para Negri (2014), no setor hospitalar existe a classificação quanto ao perfil assistencial dos estabelecimentos, sendo eles: Hospital de clínicas básicas, hospitalgeral, hospital especializado, hospital de urgência, hospital universitário e de ensino e pesquisa. $\mathrm{E}$ classificação quanto ao nível de complexidade das atividades prestadas pela unidade hospitalar: Hospital de nível básico ou primário, secundário, terciário ou quaternário em cada estabelecimento (atenção básica, de média complexidade ou de altacomplexidade).

\section{Logística Hospitalar}

A logística hospitalar é uma ação que gerencia de maneira estratégica e racional as aquisições, movimentações e armazenamentos dos materiais medico hospitalares, esses processos trabalham os recursos materiais, financeiros, pessoas e informações envolvidas nas atividades gerenciais de uma determinada organização. Empregue em uma instituição de saúde, é uma ação que gerencia de maneira tática e racional esses processos, isso acontece de modo a facilitar a proteção da saúde dos pacientes comótima qualidade de atendimento, baixo custo e soma positiva para a unidade hospitalar (SOARES, 2017).

Todo o processo acontece de forma a possibilitar os cuidados necessários para com a vida ou recuperação dos pacientes oferecendo qualidade no atendimento, tempo hábil, custo acessível e resultado positivo para a organização. Esse processo envolve desde a programação de entrada na organização, até o descarte de matérias com finalidade de garantir seguridade aos colaboradores e pacientes.

No sistema de gestão e logística em uma unidade de saúde tudo é feito de formaa garantir a eficácia de suas atividades, que são executadas de acordo com a cadeia de suprimentos que planeja, programa e controla o fluxo direto e o armazenamento eficiente. Uma cadeia de suprimentos propõe realizar a gestão de todas as ações

associadas a organização interna e externa de um a empresa, proporcionando a interações entre todos os que compõem a cadeia, como fornecedores, consumidores e prestadores de serviço, a boa gestão desses processos é importante para o bom atendimento do cliente, para o faturamento e finanças da unidade de saúde (SOARES, 2017).

O principal objetivo da organização da saúde é fornecer aos pacientes um atendimento eficaz, no entanto, logística e gerenciamento inadequados muitas vezes pode impedir que esse objetivo seja alcançado. O processo logístico do hospital é uma rede, ou seja, para atingir a meta gestão e logística devem atuar juntas, isso tem um efeito positivo no equilíbrio financeiro 
da instituição e na segurança sanitária das pessoas. Com as tendências tecnológicas na área da saúde tudo fica mais tranquilograças à automação, softwares ou ferramentas de gestão costuma oferecer maior segurança, o que significa mais benefícios para a instituição (SOARES, 2017).

Para Fonseca (2016) a logística hospitalar trás mudanças importantes no cenário da saúde, gerando novas ideias para melhorar a qualidade do setor para todos, com mais segurança e transparência. A Logística hospitalar de alta qualidade gera maior eficiência econômica, processos de compras aprimoradas, controle real de estoque, redução de erros de medicação, maior segurança para gestores, profissionais de saúde e pacientes e uma maior receita para hospitais.

Apesar de bem amplo, pode-se citar 5 dos processos de gestão logística hospitalar para insumos médicos e medicamentos eficientes (FONSECA, 2016):

1. Armazenamento e controle de processos via automação - garante que o produto certo, na quantidade certa, tenha armazenagem controlada e destino correto, com total rastreabilidade de processos, prazos e validades.

2. Individualização dos medicamentos com serialização - customização de embalagens que permite que os produtos possam ser administrados de acordo com a dose prescrita para cada paciente, sem sobras e desperdícios e assegurando que o paciente certo recebao medicamento correto.

3. Rastreabilidade dos medicamentos e insumos - acompanhamento através de código de barras de toda a rota do medicamento, desde a entrada no centro de distribuição, armazenamento, distribuição às unidades de saúde e administração no leito. Processo que garante controle de estoque, segurança de administração e maior facilidade de gestão em ações de recall.

4. Logística reversa - Processo que retorna os produtos não utilizados ao centro de distribuição, almoxarifados ou farmácias, garantindo maior aproveitamento e economicidade aos gestores da saúde.

5. Relatórios real time com projeções e indicadores - mapeamento de todo o fluxo para gestão de medicamentos, controle de estoque e demandas de cada unidade, reportados com a antecedência necessária para a realização de novos processos de compras.

O processo de logística hospitalar é uma teia, e para que o objetivo seja alcançado, a gestão e a logística devem trabalhar em conjunto. Isso traz um impacto positivo para o 
equilíbrio financeiro da instituição. Todos esses processos acima citados que fazem parte do gerenciamento da cadeia de abastecimento devem acontecer de modo a possibilitar a proteção da vida e recuperação da saúde dos pacientes, com a melhor qualidade e atendimento, baixo custo e resultados para a unidade hospitalar.

\section{Logística e Gestão de Compras Hospitalares}

É comum as pessoas não conhecerem o processo logístico de um hospital,porém, se esse processo for mal administrado ou for entregue a profissionais nãoqualificados isso terá um impacto negativo na sociedade, a falta de materiais e equipamentos médico hospitalares levam a suspensão temporária ou definitiva dosserviços de saúde e podem causar danos ao paciente a ideia central da gestão delogística hospitalar é garantir o produto certo na hora certa e para o paciente certo (SILVA, 2016).

Exercer uma boa gestão de compras hospitalares exige principalmente saber lidar com uma das atividades mais importante da logística hospitalar, que é a escolha dos fornecedores com as melhores condições. Firmar parceria é uma das maneiras que possibilitam garantia de qualidade dos materiais e serviços nas instituições de saúde para ofertar um atendimento com excelência Essa competência não exige apenas comprar produtos com preço mais em conta, mais sim assegurar o melhor custo benefício, incluindo prazo e agilidade na entrega, condição de pagamento e qualidade.

O departamento de compras é o setor que centraliza essas atividades e que está ligado diretamente ao setor financeiro, logo a qualidade dos produtos e serviços prestados irão influenciar a lucratividade e desempenho da unidade. Designado a este setor a responsabilidade por dirigir os processos de negociação, averiguação da procedência dos materiais e equipamentos a serem adquiridos. Investimentos em

maquinários de primeira linha, tecnologia de ponta e os processos de reparos adequados dão credibilidade a unidade que se sobressai diante de outras (SANTOS, 2018).

Dentro dessa gestão é realizado um levantamento de relatório diário, onde são identificados os medicamentos e materiais classificados como urgentes, penitentes a compras com maior frequência. É importante essa gestão de controle, tempo e estoque para analisar o tempo gasto com o todo o processo, pois a má gestão desse processopode gerar diversos problemas, como exemplo: demora no atendimento, prejuízo para a imagem institucional, perdas financeiras, dentre outras (SANTOS, 2018). 


\section{Gestão de Compras Hospitalares}

Dentro de uma instituição hospitalar, a administração da compra é essencial para manter o bom funcionamento dos seus serviços, no entanto, o setor responsável deve confiar em estratégias bem definidas e dependendo da gestão correta das comprashospitalares. Nesse sentido, é bastante comum associar um processo de compra eficiente a procurar preços menores. No entanto, o gerente deve estar ciente do fato de que não hábons resultados na compra de materiais com menor custo se a qualidade for menor. Ou seja, na gestão de compras hospitalares, a relação custo-benefício é apenas uma pequenaparte do processo. Afinal, há muitas variáveis dentro de um setor complexo, com uma ampla gama de suprimentos. E para satisfazer esses pedidos de forma eficiente, énecessário gerenciar estratégias que ajudem no processo de tomada de decisão (ALMEIDA, 2020).

Para Almeida (2020), traçar estratégias de desempenho são tão fundamentais quanto nos processos que implicam maior complexidade. Portanto, algumas medidas são recomendadas para a compra e gerenciamento. Alguns dos processos são:

- Centralizar a gestão de compras, ou seja, centralizar as atividades dentro do setor de compras faz com que os coordenadores submetam seus pedidos dentro de um período determinado para que sejam feitas as cotações, esse processo permite reunir um número maior de fornecedores e aumentar as possibilidades de negociação.

- Evitar compras emergenciais, pois se corre o risco de adquirir produtos com valores mais altos e em quantidades insuficientes, assim, se observa uma ineficiência da gestão de compras quando ocorre falta ou sobra de insumos.

- Basear a gestão em dados, pois ao adotar um sistema informatizado de gestão, as compras podem ser baseadas nos dados armazenados. Informações como consumo médio mensal, média de preço por item, tempo de entrega, entre outras,facilitam na tomada de decisão e tornam o processo mais eficiente.

- Melhorar o armazenamento de insumos, pois o armazenamento adequado dos produtos hospitalares faz parte das boas práticas da gestão de compras. Mesmo que os dados do sistema sejam compatíveis com o estoque, observar tais condições é fundamental. Inclusive porque o controle de temperatura e umidade é obrigatório para manter a integridade dos insumos. 


\section{Metodologia}

A pesquisa se baseia em um estudo de caso em um hospital privado de baixa média complexidade na cidade de Imperatriz/Ma. O estudo de caso é um método qualitativo que geralmente consiste em uma maneira de aprofundar uma unidade individual. Serve-se para responder a perguntas que o pesquisador não tem muito controle sobre o fenômeno estudado (OLIVEIRA, 2006). O estudo de caso ajuda a entender melhor os fenômenos individuais, os processos organizacionais e políticos da sociedade. É uma ferramenta usada para entender a forma e as razões que levaram auma decisão específica. De acordo com Yin (2001), o estudo de caso é uma estratégia de pesquisa compreendendo um método que cobre tudo em abordagens específicas para a análise de coleta e dados.

A empresa estudada é uma instituição privada de caráter espesso onde seuatendimento é voltado a clientes que efetuam pagamento direto ou que possuem um plano de saúde conveniado a unidade hospitalar. Este hospital foi escolhido por sua disponibilidade e por se diferenciar dos demais hospitais locais, com relação a máquinas e equipamentos de alta performance e tecnologia, a logística de planejamento e gestãode estoque. O hospital foi fundado em 02 de janeiro de 1989 na cidade de Imperatriz MA. Em quesito assistencial, o hospital é classificado como geral e Especializado em Cardiologia e Ortopedia.

Ao longo desses 32 anos o hospital passou por diversas mudanças. Ampliou sua estrutura física, aumentou o número de leitos de internação (28 leitos) e de Unidade de Terapia Intensiva (UTI) (10 leitos), expandiu sua estrutura de atendimento, contando com uma UTI moderna, Pronto Socorro, Centro Cirúrgico, Centro de Cardiologia e Ortopedia, entre outros. Atualmente com um total de 38 leitos, conta com uma equipe

administrativa e assistencial que também cresceu na mesma proporção e hoje o hospital apresenta um quadro de 230 colaboradores.

$\mathrm{O}$ estudo de caso de natureza qualitativa elencou-se a pesquisas documentais, bibliográficas, observação de vivência interna e entrevista semiestruturada, os dados coletados foram no modelo de pesquisa narrativa. $\mathrm{O}$ método qualitativo de pesquisa é aqui entendido como aquele que se ocupa do nível subjetivo e relacional da realidade social e é tratado por meio da história, do universo, dos significados, dos motivos, das crenças, dos valores e das atitudes dos atores sociais (MINAYO, 2013).

No hospital existe o departamento de Suprimentos no qual se subdivide em três setores, são eles: Compras, Almoxarifado Central e Farmácia Central. Por intermédio dadescrição da

545 Id on Line Rev. Mult. Psic. V.15, N. 55, p. 534-552, Maio/2021 - ISSN 1981-1179

Edição eletrônica em http://idonline.emnuvens.com.br/id 
logística do departamento de suprimentos do hospital é possível discutir os principais objetivos ligados ao departamento de compras, ao recebimento de medicamentos e materiais e os métodos de dispensação mais adequados. O setor de compras tem por objetivo processar as aquisições de bens que a organização necessita.O termo compra é entendido como uma das funções da gestão de materiais ou de suprimento que envolve as seguintes famílias de atividades: seleção de materiais, gestãode estoque, compras e armazenagem. O setor de Almoxarifado Central é responsável pelo recebimento de insumos, conferência, avaliação de fornecedores, armazenagem e dispensação de materiais medico hospitalares, equipamentos e medicamentos. O setor de farmácia Central executa todo o processo de dispensação de materiais emedicamentos para os postos, pronto socorro, farmácia satélite, Centro Cirúrgico (CC) eUnidade de Terapia Intensiva (UTI).

De acordo com Pereira et al, (2005), a farmácia hospitalar e o departamento de suprimentos movimentam um volume de capital somente inferior à folha de pagamentosde um hospital, motivo pelo qual os administradores desses setores deverão semprezelar pela pontualidade, pelo menor tempo de giro de estoque possível e máximo prazo para pagamento dos materiais e medicamentos com o objetivo de reter o mínimopossível do capital de giro nas prateleiras da farmácia ou almoxarifado, bem como dos subestoques em enfermarias e centros cirúrgicos.

O departamento de suprimentos é composto atualmente por uma equipe de colaboradores formada por 18 pessoas, atuando no setor de compras, almoxarifado central e farmácia central. Desses setores, o setor de compras é o único que trabalha diretamente com a ferramenta Plannexo, ferramenta esta que ajuda a aprimorar o relacionamento do hospital com seus fornecedores, permitindo fazer avaliações personalizadas para sua operação incluindo análises em gráficos, facilitando a visualização para criar planos de ação dos pontos críticos da sua cadeia de suprimentos. E foi este o setor selecionado para a coleta de dados através de entrevista.

\section{Resultados e Discussões}

A logística do hospital vem passando por profundas transformações, e as discussões mais atuais buscam implementar técnicas adequadas de gestão de suprimentos sem diminuir a qualidade do serviço de saúde prestado aos pacientes. O maior problema identificado está nas atividades de logística hospitalar interna, assim como citado no referencial é comum 
ocorrer falta de material e medicamento provindos de uma má logística hospitalar, então foram realizadas entrevistas na instituição no intuito de analisar o seu atual mapeamento de processos.

Conforme o autor Almeida (2020) informou que traçar estratégias de desempenho são tão fundamentais quanto nos processos que implicam maiorcomplexidade diante das medidas que são recomendadas para a compra e gerenciamento do estoque, confirma-se então que a implantação de uma ferramenta tecnológica para melhorar o desempenho dos processos se faz necessária. Em agosto de 2020 o hospital introduziu a ferramenta chamada Plannexo que é uma plataforma da Bionexo, pioneira no mercado e possui um conjunto de soluções digitais que permitem às instituições realizarem a gestão online de toda a área de suprimentos. Então ohospital utiliza dos serviços da Plataforma para adquirir materiais, medicamentos e demais gêneros que dão suporte ao atendimento e contribuem para a funcionalidade do Hospital, se tornando um grande diferencial competitivo.

Desde que sua utilização foi iniciada no hospital, essa ferramenta permitiu uma redução de produtos em excesso no estoque, minimizou a espera por materiais e medicamentos, trazendo mais rentabilidade para o hospital, além de obter um melhor desempenho contando com o apoio dos setores de dispensação, compras, recebimento e almoxarifado buscando meta de ser um dos melhores planejadores, além de aperfeiçoaro seu atendimento, conforme a demonstração de posição de estoque em excesso demonstrada na figura 01 a seguir:

Figura 01: Demonstração de posição de estoque em excesso desde agosto de 2020 até março de 2021

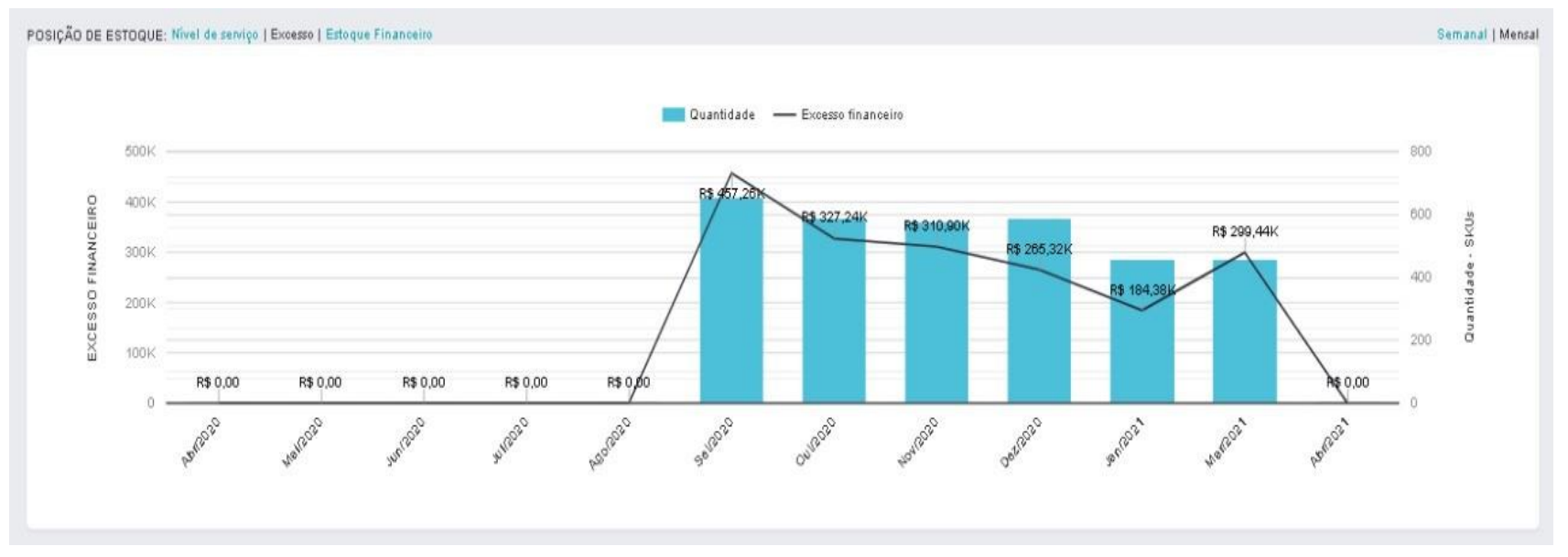

Fonte: Estudo de caso 
Nota-se na imagem o nível de redução de excesso financeiro nos respectivos meses, em agosto de 2020 quando iniciado o uso da ferramenta apresentava excesso financeiro acima de $\mathrm{R} \$ 400.000,00$ e em janeiro de 2021 há uma queda considerável para $\mathrm{R} \$ 200.000,00$. Em março de 2021 houve um aumento para a faixa de $\mathrm{R} \$ 300.000,00$ devido ao novo pico pandêmico decorrente da Covid-19.

Conforme Soares (2017), graças a automação, as tendências tecnológicas na áreada saúde tudo fica mais tranquilo, logo softwares ou ferramentas de gestão costuma oferecer maior segurança, o que significa mais benefícios para a instituição, isso de fato confirma que os processos envolvidos na logística hospitalar estão sendo gerenciados e executados de forma interligada, encerrando-se com o processo de entrega final para os setores. O principal problema identificado foi o grande excesso de materiais e medicamentos, gerando o congelamento de capital em estoque e afetando principalmente o setor financeiro da instituição. Para a resolução deste problema verificou-se a importância do uso da ferramenta Planexxo para equilibrar o mapeamento dos processos realizados no departamento de suprimentos, influenciando nos resultados finais do sistema.

Foi visto ainda que existe um dilema entre o custo de manutenção do estoque excessivo, e o custo de comprar exatamente o solicitado a um preço mais caro, eliminando os excessos de acordo com as contribuições do fornecedor.

Existem no mercado inúmeros métodos, ferramentas e profissionais focados em transformar o processo de logística hospitalar, e, principalmente, tornar o departamento de suprimentos mais inteligente. O sistema de planejamento de demanda pode ser considerado um diferencial competitivo na rede de suprimentos existente, porémidentificouse a necessidade da interligação entre este sistema e o ERP existente.

\section{Considerações Finais}

O objetivo geral deste estudo foi analisar e destacar a importância da logística hospitalar para a melhoria da competitividade de um hospital privado de baixa e média complexidade. Fruto da pesquisa realizada pode se concluir que a gestão da logística de materiais médicos hospitalares exige um planejamento para a redução no nível de perda de materiais, no nível de custos e para que haja ainda um acompanhamento do tempo devida dos materiais. Com a grande necessidade de um controle e gerenciamento de estoque no setor hospitalar, verificou-se a importância do uso da ferramenta Plannexo que está interligada ao 
ERP utilizado pelo hospital (SOUL MV), trazendo soluções de gestão de estoque e planejamento de demanda.

Comparando os resultados com os estudos de Santos 2018, percebe-se que há semelhanças no que tange ao chamado de planejamentos de relatórios diários, onde são apontados os medicamentos e materiais classificados com baixa e excesso de estoquenas Curvas A e B, C e Urgentes. Essa gestão de controle e estoque é importante para analisar o tempo gasto com o processo, logo a má gestão desse processo pode gerar problemas como perdas financeiras, que foi um dos problemas identificados no estudo de caso. Portanto a implantação da ferramenta favoreceu a qualidade da gestão de estoque eficiente e possibilitou que as atividades do setor logístico do hospital fossem aprimoradas.

Contudo a avaliação e as análises desenvolvidas neste trabalho são válidas por sua vasta contribuição ao entendimento das dificuldades e das limitações existentes nos processos realizados no setor de suprimentos com relação ao setor de compras. Ao destacar quais são as dificuldades desses processos, as pessoas que compõem o setor de suprimentos têm a possibilidade de fazer ajustes, redimensionar seu estoque e propor melhorias. Dessa maneira, esse processo poderá desempenhar um papel ainda mais relevante na logística hospitalar, por meio da redução de gastos, alcançando um quantitativo ideal para não ficar com uma demanda abaixo do que se espera e nem com nível alto de excesso. Além de poder ainda realizar um melhor planejamento de demanda de compras de materiais e medicamentos. Além disso, esta pesquisa se torna válida para o setor de suprimentos de outros hospitais, que poderão identificar potenciais oportunidades de melhoria em seu setor.

Por fim, foi possível constatar que o hospital conseguiu reduzir os custos com estoque, descartando a possibilidade de desperdícios através da adoção de um modelode gestão de logística hospitalar eficiente. Embora o artigo tenha sido desenvolvido comrigor científico, destaca-se como limitação o fato de ter pesquisado um único hospital privado. Desta forma, como recomendação para a realização de futuras pesquisas,sugere-se que a pesquisa possa ser replicada em outros hospitais públicos e privadospara confirmar ou refutar as conclusões aqui apresentadas.

\section{Referências}

ALMEIDA, Lucas. Gestão de compras hospitalares: quais as melhores estrategias. 28 de Jul de 2020. Disponível em: < https://nexxto.com/gestao-de-compras-hospitalares-quais-asmelhores-estrategias/> Acesso em 26 de abril de 2021. 
BARBIERI, Jose Carlos. MACHLINE, Claude. Logistica hospitalar. 02. Ed. São Paulo: Saraiva, 2013.

BARBIERI, José Carlos. MACHLINE, Claude. Logistica hospitalar: Teoria e Prática. 03. Ed. São Paulo: Saraiva, 2017.

BRASIL. Ministério da Saúde. Secretaria de Atenção à Saúde - Portaria 312 de 2 demaio de 2002. Disponível em < https://www.cff.org.br/userfiles/file/portarias/312.pdf> Acesso 26 de abril 2021.

BRASIL. Ministério da Saúde. Secretaria de Atenção à Saúde. Departamento deRegulação, Avaliação e Controle. Manual do Cadastro Nacional dos Estabelecimentos de Saúde/ CNES - Versão 2 - Atualização. Disponível em:

<http://bvsms.saude.gov.br/bvs/publicacoes/07_0066_M.pdf> Acesso 26 de abril de2021.

CAXITO, Fabiano et al. Logistica: um enfoque prático. 03. Ed. São Paulo: Saraiva Educação, 2019.

CHASTAGNIER, Paola Derriaux. A importancia da logistica para as empresas. 28 Agos 2013. Disponível em: <https://administradores.com.br/artigos/a-importancia-da-logistica-paraas-empresas> Acesso em 25 abril 2021.

COSTA, João Paulo. DIAS, Joana Matos. GODINHO, Pedra. Logistica. Ed.Imprensa da Universidade de Coimbra, 2010.

COSTA, J. C. N; GALVÃO, C. R. Gestão de Materiais. In PEREIRA, L. L, GALVÃO, C. R.; CHANES, M \{Org.\}. Administração Hospitalar. Instrumentos paragestão profissional. São Paulo: Loyola, 2005.

COSTA, Marcos Aurelio da. Atividades e funções da logistica. 20 Set 2018. Disponível em: $<$ https://www.logisticadescomplicada.com/atividades-funcoes-logistica/> Acesso em 25 abril 2021.

FONSECA, Talitta. Logistica empresarial. 13 Jun 2018. Disponível em: < https://pt.linkedin.com/pulse/log\%C3\%ADstica-empresarial-atividadesrim\%C3\%A1rias-e-de-apoio-talitta-fonseca> Acesso em 26 abril 2021.

FONSECA, Mayuli. 5 passos essenciais para uma logisticahospitalar de qualidade. 02 Mai 2016. Disponível em: <https://www.saudebusiness.com/hospital/5-passos-essenciais-para-umalogstica- hospitalar-de-qualidade> Acesso em 18 abril 2021.

GRANT, David B. Gestão de logistica e cadeia de suprimentos. 01. Ed. São Paulo: Saraiva, 2013.

MINAYO, M. C. S. O desafio do conhecimento: Pesquisa qualitativa em saúde. SãoPaulo: Hucitec, 2013. 
TGDI. Como organizar a gestão de compras hospitalares e superar desafios. 22 Out 2020. Disponível em: <https://tdgibrasil.com/gestao-de-compras-hospitalares/ > Acesso em 21 Mar 2021.

PORTOGENTE. logistica - o que é, evolução e atuação profissional. 2018. Disponível em: $<$ https://portogente.com.br/portopedia/101405-logistica-o-que-e-evolucao-e-atuacaoprofissional> Acesso em 16 abril de 2021.

MARTEL, Alain. VIEIRA, Darli Rodrigues. Análise e projetos de redes logisticas. 02. Ed. São Paulo Saraiva, 2010.

MEIRIM, Helio. Atividades primarias de logistica. 2017. Disponível em: <https://portogente. com.br/noticias/opiniao/94718-atividades-primarias-de- logistica> Acesso em> 26 abril de 2021.

NASCIMENTO, Luiz Roberto. Logistica - atividades secundarias. 03 de Mar de 2019. Disponível em: < https://professorluizroberto.com/logistica-atividades-secundarias/> Acesso em 26 de abril de 2021.

NEGRI, Armando de. O papel do hospital na rede de atenção a saúde. 2014. Disponível em: $<$ https://www.conass.org.br/consensus/armando-de- negri-o-papel-hospital-na-rede-deatencao- $\quad$ saude/\#: :text=1)\%20Porte\%20do\%20hospital\%3A,de\%20151 $\% 20 \mathrm{a} \% 20500 \% 201$ eitos. > Acesso em 26 de abril de 2021.

NETTO, Ronderley Miguel. Custos logisticos. Disponivel em: <http://www.guialog.com.br/Y521.htm > Acesso em: 17 Abr 2021.

NOBREGA, Tiago. História da logistica. 08 Dez 2010. Disponível em: $<$ https://administradores.com.br/artigos/historia-da-logistica> Acesso em 25 Abr 2021.

OLIVEIRA, Emanuelle. Estudo de caso. 04 de Jun de 2006. Disponível em: < https://www.infoescola.com/sociedade/estudo-de-caso/> Acesso em 26 de Abr de 2021.YIN, Roberto K. Estudo de caso: planejamento e métodos. $2^{\text {a }}$ Ed. Porto Alegre. Editora:Bookmam. 2001.

OLIVEIRA, Francisco. A evolução da logistica. 30 Mar 2011. Disponivel em: <https://administradores.com.br/artigos/a-evolucao-da-logistica> Acesso em: 18 Abr 2021.

PORTAL EDUCAÇÃO. Classisficando o porte de um hospital. 01 de

Mar 2020. Disponivel em: <
https://siteantigo.portaleducacao.com.br/conteudo/artigos/enfermagem/classificando-oporte-de-um-hospital/29118> Acesso em 26 de Abr 2021.

PORTOGENTE. Manuseio de materiais. 01 DE Jan de 2016. Disponivel em: < https://portogente .com.br/portopedia/83713-manuseio-de-materiais> Acesso em 26 de abril 2021.

SANTOS, Grace Leite. O que é preciso saber sobre gestão decompras hospitalares. 19 Jun 2018. Disponível em: < https://www.pixeon.com/blog/gestao-de-compras-hospitalares/> Acesso em 18 Abr2021.

551 Id on Line Rev. Mult. Psic. V.15, N. 55, p. 534-552, Maio/2021 - ISSN 1981-1179

Edição eletrônica em http://idonline.emnuvens.com.br/id 
SENIOR. A importancia da logistica empresarial para os negócios. 25 Nov 2019. Disponível em: <https://www.senior.com.br/blog/a- importancia-da-logistica-empresarial-para-osnegocios> Acesso em: 17 Abr 2021.

SILVA, Randler. Logisticca hospitalar. 13 de Set de 2016. Disponivel em: < https://administradores.com.br/artigos/logistica-hospitalar> Acesso em 26 Abr 2021.

SOARES, Fernando. Logistica hospitalar: o que é e sua necessidade. 31 Jan 2017. Disponível em: < https://cmtecnologia.com.br/blog/logistica-hospitalar/> Acesso em 18 Abr 2021.

\section{Como citar este artigo (Formato ABNT):}

CRUZ, Márcia Lima dos Santos; SOUSA, Josiano César de . A Logística Hospitalar como diferencial competitivo: Um estudo de caso em um hospital privado de baixa e média complexidade na cidade de Imperatriz-MA. Id on Line Rev.Mult. Psic., Maio/2021, vol.15, n.55, p. 534-552, ISSN:1981-1179.

Recebido: 28/04/2021

Aceito: 07/05/2021 